\title{
Budget impact analysis of cervical cancer screening in Portugal: comparison of cytology and primary HPV screening strategies
}

Angela Pista ${ }^{1 *}$, Carlos Costa ${ }^{2}$, Conceição Saldanha ${ }^{3}$, José Alberto Fonseca Moutinho ${ }^{4,5}$, José Maria Moutinho ${ }^{6}$, Fernando Arrobas ${ }^{7}$, Carlos Catalão ${ }^{8}$ and Jari Kempers ${ }^{9}$

\begin{abstract}
Background: Primary Human Papilloma Virus (HPV) testing is the currently recommended cervical cancer (CxCa) screening strategy by the Portuguese Society of Gynecology (SPG) clinical consensus. However, primary HPV testing has not yet been adopted by the Portuguese organized screening programs. This modelling study compares clinical benefits and costs of replacing the current practice, namely cytology with ASCUS HPV triage, with 2 comparative strategies: 1) HPV (pooled) test with cytology triage, or 2) HPV test with 16/18 genotyping and cytology triage, in organized CxCa screenings in Portugal.

Methods: A budget impact model compares screening performance, clinical outcomes and budget impact of the 3 screening strategies. A hypothetical cohort of 2,078,039 Portuguese women aged 25-64 years old women is followed for two screening cycles. Screening intervals are 3 years for cytology and 5 years for the HPV strategies. Model inputs include epidemiological, test performance and medical cost data. Clinical impacts are assessed with the numbers of CIN2-3 and CXCa detected. Annual costs, budget impact and cost of detecting one CIN2+ were calculated from a public healthcare payer's perspective.

Results: HPV testing with HPV16/18 genotyping and cytology triage (comparator 2) shows the best clinical outcomes at the same cost as comparator 1 and is the most cost-effective CxCa screening strategy in the Portuguese context. Compared to screening with cytology, it would reduce annual CxCa incidence from 9.3 to 5.3 per 100,000, and CxCa mortality from 2.7 to 1.1 per 100,000. Further, it generates substantial cost savings by reducing the annual costs by $€ 9$. 16 million (- 24\%). The cost of detecting CIN2+ decreases from the current $€ 15,845$ to $€ 12,795$. On the other hand, HPV (pooled) test with cytology triage (comparator 1) reduces annual incidence of CxCa to 6.9 per 100,000 and CxCa mortality to 1.6 per 100,000, with a cost of $€ 13,227$ per CIN2+ detected with annual savings of $€ 9.36$ million (- 24\%). The savings are mainly caused by increasing the length of routine screening intervals from three to five years.

Conclusion: The results support current clinical recommendations to replace cytology with HPV with 16/18 genotyping with cytology triage as screening algorithm.
\end{abstract}

Keywords: Cervical cancer, Screening, HPV, HPV 16/18 genotyping, Cytology, Budget impact 


\section{Background}

Cervical cancer $(\mathrm{CxCa})$ is one of the most common cancers in women, with nearly 500,000 new cases being diagnosed each year worldwide [1]. Its prevalence represents relevant costs for patients, their families and countries. Insiga et al. [2] reported that $75 \%$ of $\mathrm{CxCa}$-diagnosed women died before sixty and 25\% before turning forty. Researchers also estimated that $29 \%$ of them would be professionally active in the year they died and, based on their salaries' projections, represented a revenue loss of 1.3 Billion USD, a figure superior to the direct costs associated with $\mathrm{CxCa}$ in the US. The introduction of cervical cytology as a screening method in the mid-twentieth century contributed to a decrease in the rate of $\mathrm{CxCa}$, but its low sensitivity for $\mathrm{CIN} 2+$ requires a frequent repetition of the secreening process [3]. As a result, there is need for more efficient and cost-effective screening methods [4]. Therefore, actual knowledge lead to the definition of new strategies of prevention and practice management that include Human Papillomavirus (HPV) testing and prophylactic vaccination. Portugal started the first organized cervical cancer screening program in the Centre Region in the late 90's, extending it to more than half of the country nowadays. The HPV quadrivalent vaccine was introduced in the national vaccination program in 2008 extending the coverage to almost $90 \%$ of women. Regarding screening, the Portuguese Society of Gynaecology consensus document considers Pap Cytology with ASCUS HPV triage every three years as adequate. Nevertheless, also point out the primary high-risk HPV (hrHPV) testing with cytology triage every five years as the recommended screening algorithm [5], based on the superior sensitivity of the HPV assay, validated by prospective clinical trials. Ronco $G$ et al. (2014) [3] point out that HPV-based screening provides $60-70 \%$ greater protection against invasive cervical carcinomas when compared to Pap cytology. Following this recommendation a law decret was published in 2017 confirming HPV as the primary screening test with $16 / 18$ genotyping as a triage test for direct colposcopy and Pap cytology as a triage for other 12 hrHPV types [6], which is determining a change in the screening algorithm. Despite this fact, only some of the organized screening programs implemented the project. In this context, a comparison of the clinical and budget impact of different screening strategies will help to clarify the health care gains obtained with the adoption of the new screening algorithm. This is the first budget impact analysis to date on this subject evaluating the best scenarios for Portugal.

\section{Methods}

\section{Study population}

The modelling is carried out on a hypothetical national cohort of 2,078,039 25-64-year-old Portuguese women fitting the target age groups for cervical cancer screening.
The same cohort was used for all the three screening strategies under comparison [7], assuming exclusion of ineligible patients, such as hysterectomized women. $\mathrm{CxCa}$ screening compliance rate, attendance at re-test and next routine screening were assumed to be $70.7 \%$ [8] and $85.0 \%$ [9], respectively.

\section{Compared screening strategies}

The compared screening strategies in this evaluation were based on the Portuguese Society of Gynaecology consensus on cervical cancer screening [5]. Three primary $\mathrm{CxCa}$ screening strategies are compared. The current practice: cytology with ASCUS HPV triage every three years (Fig. 1-a). Women with normal cytology return to routine screening. Women with LSIL or worse are referred for colposcopy. ASCUS results are triaged with pooled HPV test within 6 months. HPV negative women return to routine screening and HPV-positive undergo colposcopy.

Comparator strategy 1: HPV (pooled) test with reflex cytology triage every five years (Fig. 1-b). HPV negative women return to routine screening. HPV positive results are triaged with reflex cytology. Women with cytology results ASCUS or worse are referred for colposcopy. Normal cytology results are followed up with HPV re-test in twelve months. Women with HPV-negative re-test return to routine screening and HPV-positive re-tests undergo colposcopy.

Comparator strategy 2: HPV test with 16/18 genotyping with reflex cytology triage every five years (Fig. 1-c). $\mathrm{HPV}$ negative women return to routine screening. Women with hrHPV genotypes $16 / 18$ are directly referred for colposcopy. HPV genotypes other than 16/18 (HPV+ 12 types) are triaged with reflex cytology. Women with cytology results ASCUS or worse are referred to colposcopy. Normal cytology results are followed up with HPV re-test in twelve months. Women with HPV-negative re-test return to routine screening and HPV-positive re-tests undergo colposcopy.

\section{Model structure}

An Excel-based (Microsoft Office $365^{\circ}$ ) budget impact model was developed to evaluate screening performance, clinical outcomes and budget impacts of the $\mathrm{CxCa}$ screening strategies during two routine screening cycles. The model consists of two main components: a decision-tree model and a Markov model (Fig. 2). The decision-tree simulates the performance of the screening strategies. Women are divided into three groups according to their test results; 1 ) healthy, who return to routine screening, 2) those who require follow-up testing, and 3) diagnosed CIN2-3 or $\mathrm{CxCa}$ who are treated and exit the model. The groups 1 and 2 continue to the Markov model. The Markov model simulates natural history of 

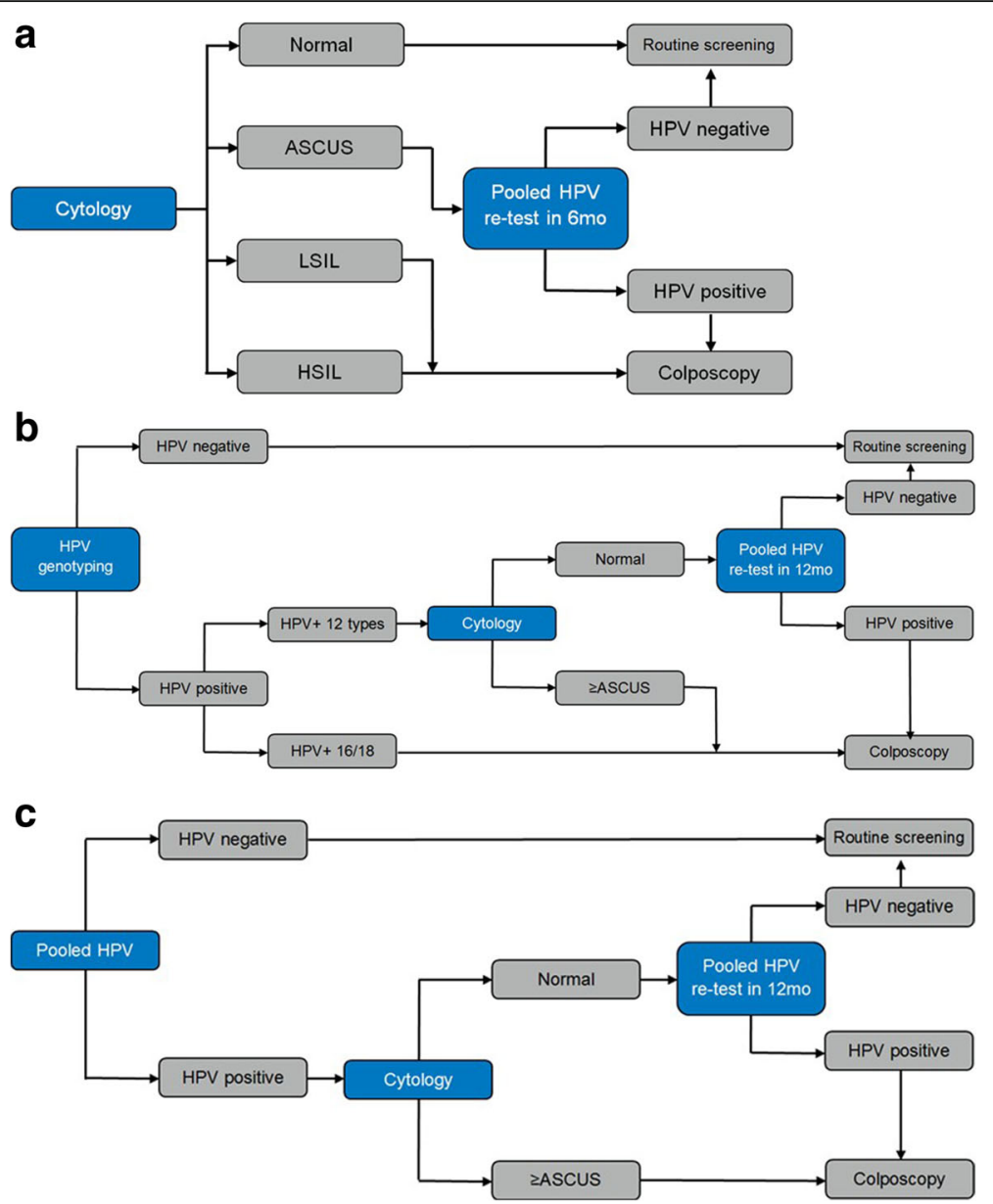

Fig. 1 a The current practice cytology with pooled HPV triage. b Comparator 1 pooled HPV with reflex cytology triage. c Comparator 2 HPV test with genotyping and reflex cytology triage

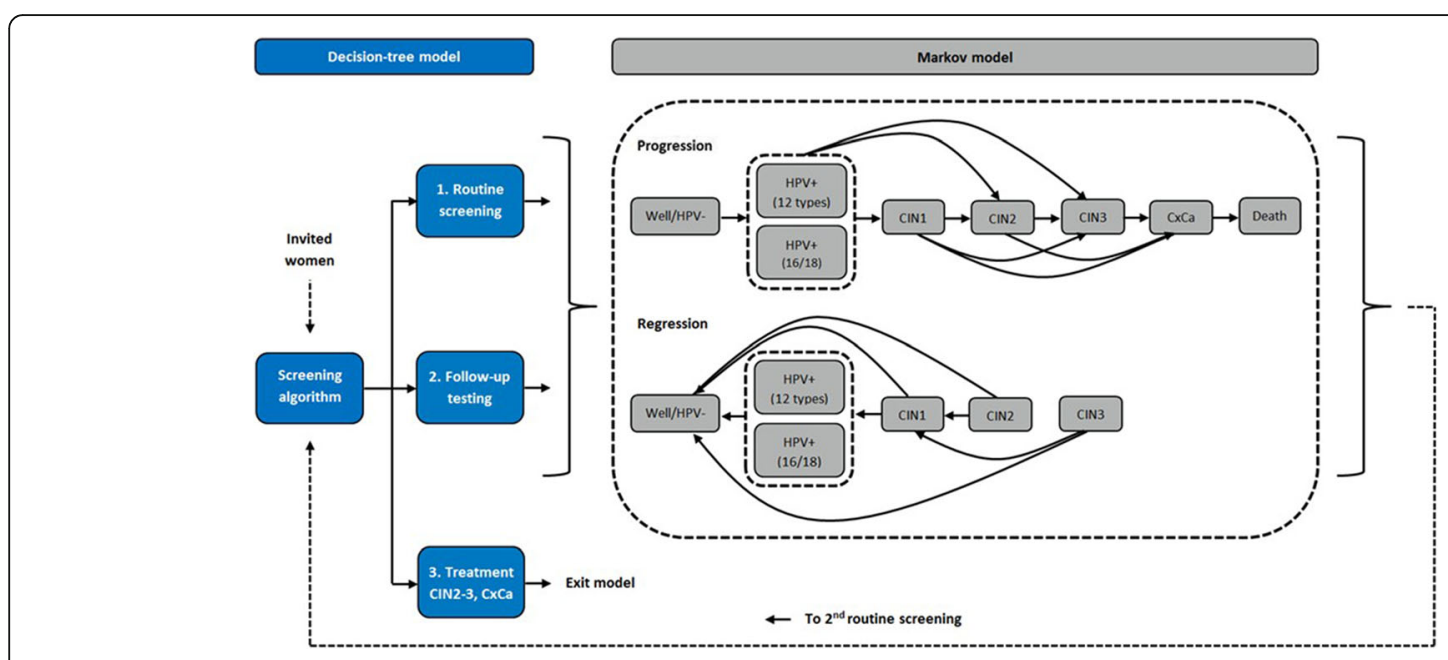

Fig. 2 The model structure and patient flow 
HPV infection, $\mathrm{CIN}$ and $\mathrm{CxCa}$ in one-month cycles. During each cycle, women can remain on the same stage, progress to the next, or regress to the previous stage. The transition probabilities between the health stages are shown in Table 1 [10-24]. The model does not differentiate between the stages of $\mathrm{CxCa}$ and only includes the probability of dying from invasive $\mathrm{CxCa}$, not considering mortality from other causes.

\section{Model inputs}

\section{Epidemiology and test performance}

The prevalence of HPV (10.5\%) and HPV genotypes 16/ 18 (2.1\%) among 25-64-year-old women are based on the CLEOPATRE epidemiological study in Portugal [25, 26]. The prevalence of CIN1 (1.4\%), CIN2 (0.4\%), CIN3 $(0.6 \%)$ and $\mathrm{CxCa}(0.048 \%)$ are taken from the ATHENA trial [27]. The US-based trial assessed the performance of Thinprep Liquid Based Cytology (Hologic) and the cobas $^{\circ}$ HPV test (Roche) in a cohort of 40,900 over 25 -year-old women [28] was chosen because it is one of the largest studies until now to compare the performance of Pap cytology, HPV test and partial genotyping in a screening population. Additionally, data from Portugal on this matte is unavailable. The test performance inputs of Liquid Based Cytology (LBC) and HPV test (pooled and 16/18 genotyping) are also based on the ATHENA trial data (Table 2) [28]. Model inputs were based on the entire cohort and not stratified by age. Data for the natural history of cervical cancer was taken from the scientific literature (Table 3). Colposcopy is assumed 100\% sensitive and specific.

\section{Costs}

The costs are divided into three main categories; screening, diagnostic and treatment. Cost inputs are based on the Portuguese diagnosis-related group (DRG) prices in 2014 and on published data (Table 4) [29-31]. Screening costs include office visits, primary, triage and re-tests. Prices for the HPV test (pooled and 16/18 genotyping) are assumed to be the same as the DRG price of cytology (€27.40) because the current DRG price for the HPV test was set for a triage scenario and so it is too high for a primary screening test for $\mathrm{CxCa}$ [29]. Diagnosis costs relate to diagnostic consultations, colposcopies and biopsies. Treatment costs include CIN2-3 and $\mathrm{CxCa}$ treatment $[30,31]$. The budget impacts are calculated from the healthcare provider's perspective and presented in Euros.

\section{Model outputs}

The performance of the screening strategies is assessed with the percentage of CIN2-3 and CxCa cases detected and with the number of colposcopies needed to detect one disease case (CIN2-3 and $\mathrm{CxCa}$ ). The clinical impacts, in the screened population, are measured with an annual incidence of $\mathrm{CxCa}$ and annual $\mathrm{CxCa}$ mortality. The costs are presented as average annual costs during the two routine screening cycles. The annual costs are used to take into consideration the different routine screening intervals. Annual budget impacts of the primary HPV screening strategies are calculated against the current practice. Further, the costs outputs include the costs per screened woman and cost of detecting a disease (CIN2-3 and CxCa).

\section{Sensitivity analysis}

A sensitivity analysis was conducted to analyse whether clinical inputs from different published scientific literature sources [32-35], other than the primary reference used, would change the budget impact outputs of the model. A sensitivity analysis was also conducted to understand how the variation of the cost of the HPV test and LBC (half vs double) would affect the budget impact of the different screening strategies.

\section{Results}

Screening performance and clinical outcomes

According to the model results, the current cytology-based screening strategy detects $51.8 \%$ of $\mathrm{CxCa}$ and $51.9 \%$ of CIN2-3 cases. Comparator strategy 1 : HPV (pooled) test with reflex cytology triage, increases the detection of $\mathrm{CxCa}$ to $81.0 \%$ and of CIN2-3 to $81.4 \%$. Comparator strategy 2: HPV 16/18 genotyping with reflex cytology triage, improves the detection of $\mathrm{CxCa}$ to $88.6 \%$ and of CIN2-3 cases to $87.3 \%$ (Fig. 3). During the two screening cycles, the screening performances of the HPV-based comparator strategies 1 and 2 reduce annual incidence of $\mathrm{CxCa}$ in the screened population from 9.3 to 6.9 and 5.3 per 100,000, respectively. Furthermore, comparators 1 and 2 reduce annual $\mathrm{CxCa}$ mortality in the screened population from cytology-based screening from 2.7 to 1.6 and 1.1 per 100,000 , respectively. This means avoiding an extra $51 \mathrm{CxCa}$ deaths per year in comparator 1 and avoiding 85 extra $\mathrm{CxCa}$ deaths per year in comparator 2 for the simulated cohort. The number of colposcopies needed to detect a disease case (CIN2-3 and $\mathrm{CxCa}$ ) also decrease from 10.1 to 8.2 in comparator 1 and 9.6 in comparator 2 (Table 5).

\section{Budget impact}

The average annual costs of the cytology-based strategy are $€ 34,43$ million. Annual costs of comparator 1 are $€ 29,07$ million and comparator 2 represent $€ 29,26$ million (Fig. 4). Both primary HPV screening strategies originate cost-savings. Comparator 1 decreases the total annual costs in $€ 9,36$ million ( $-24 \%$ ) and comparator 2 in $€ 9,16$ million ( $-24 \%)$. 
Table 1 Annual transition (progression / regression) probabilities of the Markov model; Natural history inputs for HPV infection, CIN, and cervical cancer

\begin{tabular}{lcl}
\hline & $\begin{array}{c}\text { Model } \\
\text { input }\end{array}$ & References \\
\hline $\begin{array}{l}\text { Annual Progressio } \\
\text { Well to hrHPV }\end{array}$ & $4.2 \%$ & Kulasingam et al. (2011) [10] \\
infection & & \\
Progression from hrHPV (12 types) \\
to CIN1 & $8.1 \%$ & $\begin{array}{l}\text { Kulasingam et al. (2011) [10]; Insinga } \\
\text { RP et al. (2007) [11] }\end{array}$ \\
to CIN2 & $0.1 \%$ & Khan MJ et al. (2005) [12] \\
to CIN3 & $0.1 \%$ &
\end{tabular}

Progression from hrHPV 16/18

$\begin{array}{lll}\text { to CIN1 } & 9.9 \% & \begin{array}{l}\text { Insinga RP et al. (2007) [11]; Insinga } \\ \text { RP et al. (2009) [13] }\end{array} \\ \text { to CIN2 } & 0.6 \% & \text { Khan MJ et al. (2005) [12] } \\ \text { to CIN3 } & 1.5 \% & \end{array}$

Progression from CIN1

$\begin{array}{ll}\text { to CIN2 } & 3.2 \% \\ \text { to CIN3 } & 0.9 \% \\ \text { to } \mathrm{CXCa} & 0.3 \%\end{array}$

Weighted average: Kataja $V$ et al. (1989) [14]; Holowaty P et al. (1999) [15]; Matsumoto K et al. (2006) [16]; Omori M et al. (2007) [17]; Guedes AC et al. (2010) [18]

Progression from CIN2

$\begin{array}{ll}\text { to } \mathrm{CIN} 3 & 4.2 \% \\ \text { to } \mathrm{CXCa} & 1.8 \%\end{array}$

Weighted average: Kataja $V$ et al. (1989) [14]; Holowaty P et al. (1999) [15]; Matsumoto K et al. (2006) [16]; Omori M et al. (2007) [17]; Guedes AC et al. (2010) [18]

CIN3 to CXCa $\quad 3.4 \%$

Weighted average: Kataja $V$ et al. (1989) [14]; Holowaty P et al. (1999) [15]; McCredie et al. (2008) [19]

Annual mortality rate $0.6 \%$ for $\mathrm{CxCa}$

SEER data. 5 year survival of $68 \%$ converted to annual mortality rate [20]

Annual Regression

Regression from hrHPV (12 types)
with normal
cytology to well
with borderline/
mild cytology to
well

Regression from hrHPV 16/18

\begin{tabular}{|c|c|c|}
\hline $\begin{array}{l}\text { with normal } \\
\text { cytology to well }\end{array}$ & $43.8 \%$ & Bulkmans NJ et al. (2007) [21] \\
\hline $\begin{array}{l}\text { with borderline/ } \\
\text { mild cytology } \\
\text { to well }\end{array}$ & $21.8 \%$ & \\
\hline
\end{tabular}

Regression from CIN1

$\begin{array}{lll}\text { to well } & 21.2 \% & \text { Weighted average: Kataja } V \text { et al. } \\ \text { to hrHPV } & 2.4 \% & \text { (1989) [14]; Holowaty P et al. (1999) } \\ \text { [15]; Matsumoto K et al. (2010) [22] }\end{array}$

Regression from CIN2

to well $\quad 9.4 \% \quad$ Weighted average: Kataja $\vee$ et al.
Table 1 Annual transition (progression / regression) probabilities of the Markov model; Natural history inputs for HPV infection, CIN, and cervical cancer (Continued)

\begin{tabular}{ccl}
\hline & $\begin{array}{l}\text { Model } \\
\text { input }\end{array}$ & References \\
\hline to CIN1 & $9.4 \%$ & $\begin{array}{l}\text { (1989) [14]; Meyskens FL Jr. et al. } \\
(1994) \text { [23]; Holowaty P et al. (1999) } \\
\text { [15]; Matsumoto K et al. (2006) [16]; } \\
\text { Omori M et al. (2007) [17]; Castle } \\
\text { PE et al. (2009) [24]; Guedes AC et al. } \\
\text { (2010) [18] }\end{array}$ \\
& & \\
Regression from CIN3 & & \\
to well & $3.9 \%$ & $\begin{array}{l}\text { Weighted average: Kataja V et al. (1989) } \\
\text { [14]; McCredie et al. (2008) [19] }\end{array}$ \\
to CIN1 & $1.6 \%$ & \\
\hline
\end{tabular}

Figure 4 portrays a breakdown of annual costs of the three screening strategies. Screening costs are the largest component of all the three strategies. Annual screening costs (screening and triage tests and office visits) of the current practice and comparators 1 and 2 are $€ 32,79$ million, $€ 24,41$ million ( $-25.6 \%)$ and $€ 24,30$ million $(-25.9 \%)$, respectively. Overall cost savings result from the reduction of screening costs. These cost savings are caused by the longer routine screening interval of the primary HPV screening strategies. Annual diagnosis costs (follow-up consultations, colposcopies and biopsies) of the current practice and comparators 1 and 2 are $€ 1,85$ million, $€ 1,22$ million $(-34.0 \%)$ and $€ 1,53$ million (-17.0\%), respectively. In both primary HPV screening strategies, the declining incidence of CIN2-3 and $\mathrm{CxCa}$ results in lower annual treatment costs. The treatment costs (CIN2-3 and CxCa combined) decline from $€ 1,75$ million to $€ 1,58$ million (-9.7\%) in comparator 1 and to $€ 1,49$ million $(-14.8 \%)$ in comparator 2. Average cost per screened women in the current practice and comparators 1 and 2 are $€ 18,49, € 13,99$ and $€ 14,08$, respectively. In addition, the cost of detecting a disease case (CIN2-3 or CxCa) decreases from $€ 15,845$ to $€ 13,227$ in comparator 1 and to $€ 12,795$ in comparator 2.

\section{Sensitivity analysis}

The sensitivity analysis shows that the comparator screening algorithms accuracy varies in a higher level than relative costs versus the current practice. Comparator 1 (Table 6) and 2 (Table 7) would reduce costs vs

Table 2 Prevalence of HPV, CIN and Cervical Cancer

\begin{tabular}{lll}
\hline Prevalence of hrHPV & $8.4 \%$ & Pista et al. (2013) [26] \\
\hline Prevalence of HPV16 and/or 18 & $2.4 \%$ & Pista et al. (2013) [26] \\
Prevalence of CIN1 & $1.4 \%$ & Wright et al. (2012) [27] \\
Prevalence of CIN2 & $0.4 \%$ & Wright et al. (2012) [27] \\
Prevalence of CIN3 & $0.6 \%$ & Wright et al. (2012) [27] \\
Prevalence of invasive cervical cancer & $0.048 \%$ & Wright et al. (2012) [27] \\
\hline
\end{tabular}


Table 3 Test performance inputs of cytology and Cobas ${ }^{\oplus}$ HPV test (pooled and 16/18 genotyping)

\begin{tabular}{lcl}
\hline Input & Value & Source \\
\hline Cytology (threshold ASCUS) & & \\
Sensitivity CIN2 & $52.6 \%$ & Castle et al. (2011) [28] \\
Sensitivity CIN3 & $52.8 \%$ & Castle et al. (2011) [28] \\
Sensitivity CXCa & $52.8 \%$ & assumed to be equivalent to CIN3 \\
Specificity CIN2+ & $76.1 \%$ & Castle et al. (2011) [28] \\
Cytology (threshold LSIL) & & \\
Sensitivity CIN2 & $39.2 \%$ & Castle et al. (2011) [28] \\
Sensitivity CIN3 & $40.1 \%$ & Castle et al. (2011) [28] \\
Sensitivity CXCa & $40.1 \%$ & assumed to be equivalent to CIN3 \\
Specificity CIN2 & $86.5 \%$ & Castle et al. (2011) [28] \\
Cytology (threshold HSIL) & & \\
Sensitivity CIN2 & $20.3 \%$ & Castle et al. (2011) [28] \\
Sensitivity CIN3 & $26.2 \%$ & Castle et al. (2011) [28] \\
Sensitivity CXCa & $26.2 \%$ & assumed to be equivalent to CIN3 \\
Specificity CIN2 & $98.3 \%$ & Castle et al. (2011) [28] \\
Cobas ${ }^{\oplus}$ HPV test (pooled) & & \\
Sensitivity CIN2 & $88.2 \%$ & Castle et al. (2011) [28] \\
Sensitivity CIN3 & $92.0 \%$ & Castle et al. (2011) [28] \\
Sensitivity CXCa & $92.0 \%$ & assumed to be equivalent to CIN3 \\
Specificity CIN2 & $57.8 \%$ & Castle et al. (2011) [28] \\
Cobas ${ }^{\circledR}$ HPV test with genotyping 16/18 \\
Sensitivity 16/18 CIN2 & $51.8 \%$ & Castle et al. (2011) [28] \\
Sensitivity 16/18 CIN3 & $59.5 \%$ & Castle et al. (2011) [28] \\
Sensitivity 16/18 CxCa & $65.3 \%$ & Castle et al. (2011) [28] \\
Specificity CIN2 & $75.3 \%$ & Castle et al. (2011) [28] \\
\hline & & \\
& & \\
& &
\end{tabular}

usual care if inputs from the POBASCAM and PavDag studies would be used for modelling instead of the ATHENA [32,33]. Modelling with an LBC sensitivity of 73.0\% for pap cytology sensitivity in this model (highest pap cytology sensitivity for $\mathrm{CIN} 2+$ found in the ATHENA trial) [34], would improve the clinical performance of usual care, but would not alter the cost difference towards comparator strategies. On the other hand, cutting the cost of the HPV test by half $(€ 13,7)$ would improve the savings vs usual care to $38.0 \%$ for comparators 1 and 2, while doubling the HPV test cost $(€ 54,8)$ would still save $3.0 \%$ of the screening budget for Comparator 1 or 2 .

\section{Discussion}

Overall, the output of the decision-tree and Markov model suggest the replacement of the current cytology-based screening with any of the two primary HPV screening strategies. It improves the detection of CIN2-3 and CxCa, displays better clinical outcomes and creates substantial
Table 4 Medical costs used in the model

\begin{tabular}{|c|c|c|}
\hline Parameter & Euro & References \\
\hline \multicolumn{3}{|l|}{ SCREENING COSTS } \\
\hline $\begin{array}{l}\text { Office visit (routine/repeat } \\
\text { screening) }\end{array}$ & $31.00 €$ & {$[29]$} \\
\hline $\begin{array}{l}\text { Cytology test (liquid- } \\
\text { based) }\end{array}$ & $27.40 €$ & {$[29]$} \\
\hline HPV test (pooled) & $27.40 €$ & $\begin{array}{l}\text { Assumed to have the same } \\
\text { price as for cytology test }\end{array}$ \\
\hline $\begin{array}{l}\text { HPV test with 16/18 } \\
\text { genotyping }\end{array}$ & $27.40 €$ & $\begin{array}{l}\text { Assumed to have the same } \\
\text { price as for cytology test }\end{array}$ \\
\hline \multicolumn{3}{|l|}{ DIAGNOSTIC COSTS } \\
\hline $\begin{array}{l}\text { Office visit (diagnostic } \\
\text { follow-up) }\end{array}$ & $31.00 €$ & {$[29]$} \\
\hline Colposcopy plus biopsy & $34.40 €$ & [29] \\
\hline \multicolumn{3}{|l|}{ TREATMENT COSTS } \\
\hline $\begin{array}{l}\text { Treatment for cervical } \\
\text { intraepithelial neoplasia } \\
(\text { Grade } \geq 2)\end{array}$ & $907.57 €$ & $\begin{array}{l}\text { Adapted from: Costa C [30]; } \\
\text { Santana R et al. [31] }\end{array}$ \\
\hline $\begin{array}{l}\text { Treatment for invasive } \\
\text { cervical cancer }\end{array}$ & $\begin{array}{l}10423.29 \\
€\end{array}$ & $\begin{array}{l}\text { Adapted from: Costa C [30]; } \\
\text { Santana R et al. [31] }\end{array}$ \\
\hline
\end{tabular}

cost-savings for the Portuguese healthcare system. The results are in line with similar health economic outcome research (HECON) studies [36-39] and support the current clinical consensus on the move towards molecular screening for cervical cancer not just in Portugal but also other European countries. Nevertheless, as this study is based on a computer-based model cohort, a randomized clinical trial or real-world studies with randomized samples and appropriate methodologies are needed as further research to generalize these results to the population.

The major goal of cervical cancer screening is to detect its precursor lesions and treat them before they become invasive. According to the findings of the meta-analysis of 4 European randomized trials (Swedescreen (Sweden) [40], POBASCAM (Netherlands) [41], ARTISTIC (England) [42] and NTCC (Italy) [43], reinforced by the recent findings of the COMPASS (Australia) [44] and FOCAL (Canada) [45]), HPV-based screening provides $60-70 \%$ greater protection against invasive cervical carcinomas compared with Pap cytology and that screening intervals may be extended to at least five years [3]. In the US, the Kaiser Permanente Northern California (analysing data from more than 330,000 women) [46] and the ATHENA trial (recruiting around 47,000 women) [28] confirmed the vantage of the HPV test over pap cytology as a primary screening method.

In this study, HPV 16/18 genotyping with cytology triage (comparator 2) provides better clinical impacts, while lowering the costs. Therefore, it is the most cost-effective $\mathrm{CxCa}$ screening strategy in the Portuguese context. Comparator 2 also reduces annual $\mathrm{CxCa}$ incidence and mortality and 


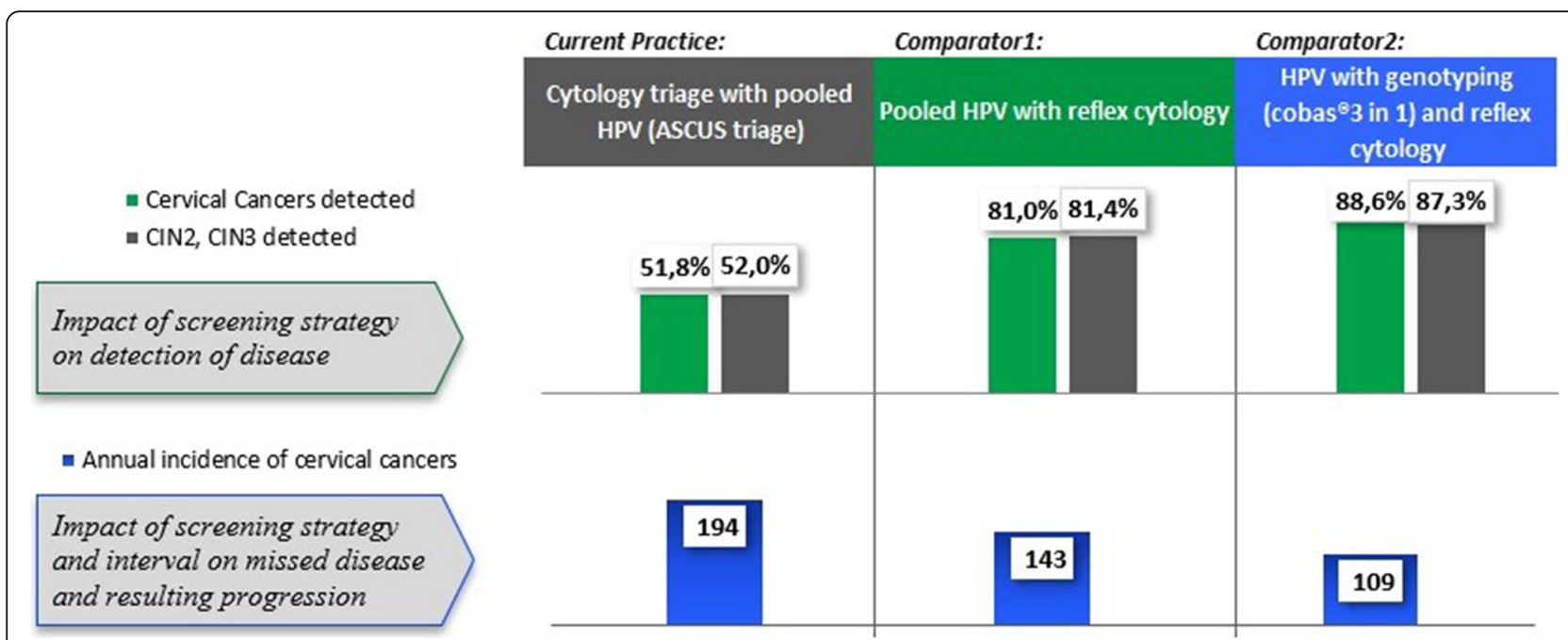

Fig. 3 Performance of the screening strategies during two screening cycles. Detected cervical cancers and CIN2-CIN3 cases

reduces the total annual screening costs in $24.0 \%$, as well as the cost of detecting a CIN2+ in 19,2\%. The screening performance of HPV (pooled) test with cytology triage (comparator 1) is lower when compared to comparator 2 in its detection rates but has similar costs. The improved clinical outcomes obtained through this HECON modelling result from an improved screening performance of both HPV strategies and an earlier detection of $\mathrm{CIN} 2-3$ and $\mathrm{CxCa}$. On the other hand, the substantial cost savings are caused by the increased length of the routine screening intervals, allowed by the enhanced sensitivity and negative predictive value of HPV based screening. The performance of Pap cytology is low in the model, but consistent with data from an international meta-analysis showing a detection rate of $53,0 \%$ [47].

Concerning the triage of HPV positive women, the authors of this study acknowledge the fact that pap cytology performance as a triage marker is affected by an expected increase in sensitivity and a decrease in specificity $[48,49]$. This means that the "real-life" sensitivity of the HPV based algorithms can be higher and specificity lower, positively impacting clinical results (CIN2+ detection) and increasing costs. To clarify this subject, a sensitivity analysis compared results from other studies that also addressed triage strategies for HPV positive women, such as POBASCAM [32], PavDag [33] and also from the ATHENA three years follow up results [34]. The conclusion was that the cost difference towards cytology-based screening remained higher, consolidating the main findings on the cost savings created by the change towards HPV test-based screening.

The model also projects a difference in clinical outcomes between comparator 1 and 2 strategies: 5.9\% in sensitivity for the detection of $\mathrm{CxCa}$. The model results suggest that if the individual tests are used in a certain strategy or algorithm then the number of detected cases may differ. Although such differences were never reported from clinical trials, they can be partially explained by the fact that in this simulation, in comparator 1 all hrHPV positive / NILM cases (including HPV16 and 18 positives) are deferred and that $15.0 \%$ of these will actually miss follow-up.

This study has certain limitations. As any modelling study, the results are influenced by the input parameters

Table 5 Annual cervical cancer incidence and mortality in the screened population (1,764,000 25-65-year-old Portuguese women) and per 100,000. The number of colposcopies required per detected disease (CIN2-3 and CxCa)

\begin{tabular}{|c|c|c|c|c|c|c|}
\hline & \multicolumn{2}{|l|}{ Current practice: } & \multicolumn{2}{|l|}{ Comparator 1: } & \multicolumn{2}{|l|}{ Comparator 2: } \\
\hline & \multicolumn{2}{|c|}{$\begin{array}{l}\text { Cytology with pooled HPV } \\
\text { triage }\end{array}$} & \multicolumn{2}{|c|}{$\begin{array}{l}\text { Pooled HPV test with reflex } \\
\text { cytology triage }\end{array}$} & \multicolumn{2}{|c|}{$\begin{array}{l}\text { HPV genotyping with reflex } \\
\text { cytology triage }\end{array}$} \\
\hline & Screened pop. & per 100,000 & Screened pop. & per 100,000 & Screened pop. & per 100,000 \\
\hline Annual CxCa incidence & 194 & 9.3 & 143 & 6.9 & 109 & 5.3 \\
\hline Annual CxCa mortality & 56 & 2.7 & 34 & 1.6 & 22 & 1.1 \\
\hline Colposcopies per disease (CIN2-2, CxCa) detected & 10.1 & & 8.2 & & 9.6 & \\
\hline
\end{tabular}




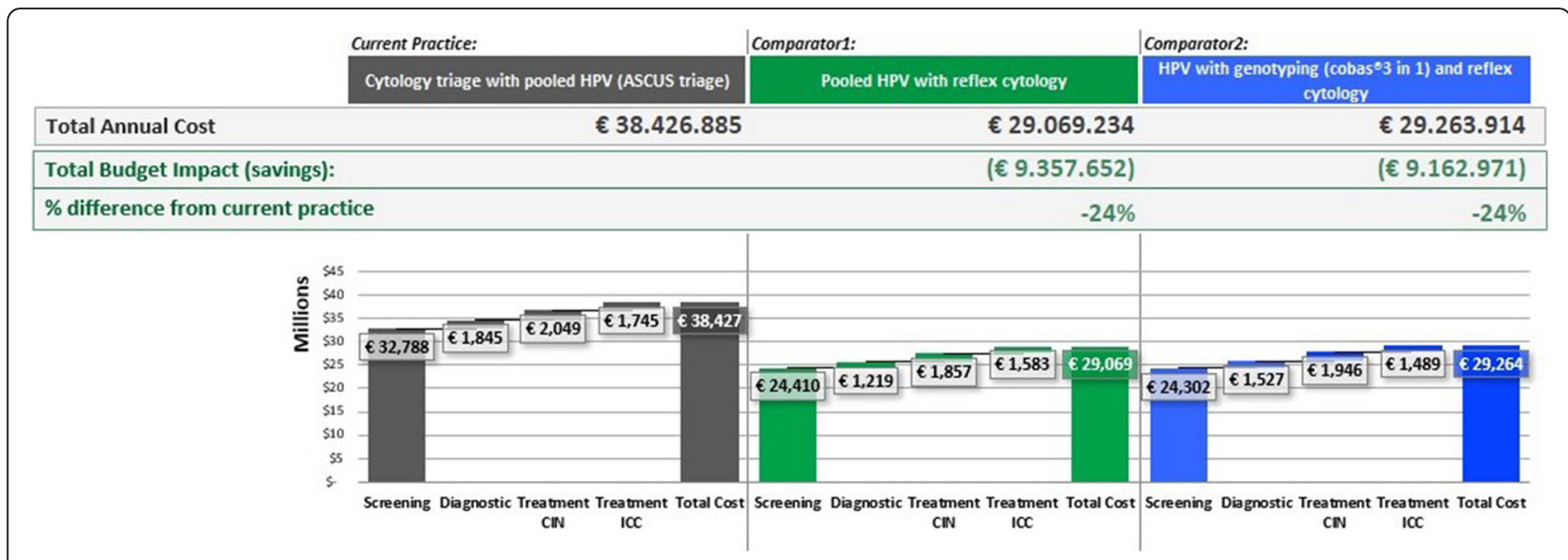

Fig. 4 Total annual costs of the screening strategies. Budget impact in comparison to the current practice. A breakdown of annual costs per screening diagnostic

and structure of the model. The performances of LBC and the HPV test (pooled and 16/18 genotyping) are based on data from a trial in the United States, not on Portuguese data. The clinical results are sensitive to changes in prevalence of HPV, HPV genotypes 16/18, CIN2 and CIN3. Also, the referral rates to colposcopy were determined in this model by the prevalence of the infection by the $14 \mathrm{hrHPV}$ types in the Portuguese epidemiological study and these may differ if prevalence changes, as it is expectable in a vaccinated population. Another model limitation is that performance data reflect the baseline test (test performance among the general population) and that the same test in a re-testing situation among a previously hrHPV+ population may be different. The authors acknowledge that the model should allow two test performance inputs - one at baseline and another for re-test situation among previously hrHPV+ women. While HPV vaccination programs impact the cost of screening programs as shown in recently published real world data [50], this model does not take that in consideration which may be considered also as a limitation.

The cost results are sensitive to changes in prices of cytology, HPV test and screening consultation. In the absence of a DRG reflecting the use of HPV as a screening test, the price of HPV tests was assumed the same as the cytology DRG. The future DRG price for an HPV test may be different. In this case, the authors tried to simulate the reality for Portugal as much as possible. In our country, there is no screening program at national level, and opportunistic and organized programs occur regionally with different levels of implementation. In the current setting, DRG prices are currently used as a reference for pricing both HPV and Cytology and the volume of tests would not allow for a cost reduction. A sensitive analysis varying the price of HPV test to either twice or half of that of cytology, shows that HPV based screening algorithms would remain cost-saving independently of the chosen scenario. Furthermore, the cost of screening can be lower if more suppliers compete in fair tenders. The guideline based on reproducibility and equivalent accuracy defined by Arbin et al. [51] is a milestone in HPV-based cervical cancer screening. There are currently $8 \mathrm{HPV}$ DNA assays fully matching these criteria, which can be recommended for HPV-based cervical cancer screening using clinician-collected cervical samples, half of which offer partial, extended or full genotyping. This means the offer is large and competitive, making public tenders able to implement either of the Comparator strategies. This is important not just for Portugal, but also for other countries. The time-horizon of this modelling study is limited to two screening cycles. Policymakers would like to understand to which level $\mathrm{CxCa}$ incidence and mortality decrease, after several screening cycles.

Table 6 Clinical performance of triaging all hrHPV+ women with LBC

\begin{tabular}{llll}
\hline Study & Sensitivity (CIN2+) & Specificity (CIN2+) & Relative cost of Comparator 1 \\
\hline ATHENA (Castle PE et al., 2011 [28]) & $88.2 \%$ & $57.8 \%$ & $-24 \%$ \\
POBASCAM (Dijkstra M et al., 2013 [32]) & $66 \%$ & $81.4 \%$ & $-26 \%$ \\
PavDag (Stanczuk GA. et al., 2017 [33]) & $68.3 \%$ & $89.1 \%$ & $-26 \%$ \\
\hline
\end{tabular}


Table 7 Clinical performance of triaging hrHPV+ women with HPV16/18 genotyping and using LBC to triage OHR

\begin{tabular}{llll}
\hline Study & Sensitivity (CIN2+) & Specificity (CIN2+) & Relative cost of Comparator 2 \\
\hline ATHENA (Wright T et al., 2014 [27]) & $93.3 \%$ & $62.8 \%$ & $-24 \%$ \\
ATHENA (Castle PE et al., 2011 [28]) & $51.8 \%$ & $75.3 \%$ & $-24 \%$ \\
POBASCAM (Dijkstra M et al., 2013 [32]) & $90.3 \%$ & $57.6 \%$ & $-25 \%$ \\
PavDag (Stanczuk GA. et al., 2017 [33]) & $93.3 \%$ & $52.7 \%$ & $-24 \%$ \\
\hline
\end{tabular}

\section{Conclusion}

The results suggest that the replacement of the current screening practice based on cytology testing every three years to HPV primary screening with cytology triage every five years improves the detection of CIN2-3 and $\mathrm{CxCa}$, provides better clinical outcomes and creates substantial cost-savings for the Portuguese healthcare system. These cost-savings are mainly generated by increasing the screening interval. Further triage of HPV positive women with partial 16/18 genotyping would improve the efficiency of the screening program. Therefore, the results of this HECON evaluation confirm the Cervical Cancer Screening recommendations of the Portuguese Society of Gynaecology [5] and the ongoing screening algorithm changes in the Portuguese organized screening programs. The results of this work also open directions for future research: a) the inputs used on this model could be refined with real world data coming from the organized screening programs, b) evaluation of the economic benefit of using emerging biomarkers like p16/ki-67 or methylation to further refine the triage of $\mathrm{HPV}+$ women and c) re-model taking vaccine immunization into consideration.

\section{Abbreviations \\ ARTISTIC: A Randomized Trial In Screening To Improve Cytology; ATHENA: Addressing The Need for Advanced HPV Diagnostics; BIM: Budget Impact Model; CIN: Cervical Intraepithelial Neoplasia; CxCa: Cervical Cancer; DGR: Diagnosis-Related Groups; HPV: Human Papillomavirus; hrHPV: High-risk Human Papillomavirus; ISPOR: International Society for Pharmacoeconomics \& Outcomes Research; LBC: Liquid Based Cytology; NTCC: New Technolog in Cervical Cancer; POBASCAM: Population Based Screening Study Amsterdam; SPG: Portuguese Society of Gyneacology}

\section{Acknowledgements}

Not applicable.

\section{Funding}

This work was supported by Roche Sistemas Diagnósticos Lda by providing the model used by the researchers and by offering to pay the Open Access publication fee. Also, as stated in the author's contribution section, employees of the sponsor reviewed and provided feedback on the model design and final manuscript. The funding body had no role in the collection of data inputs, analysis and interpretation of results.

\section{Availability of data and materials}

The model that supports the findings of this study is not public and so restrictions to the availability of these data may apply. Data may be available from the authors upon reasonable request and with permission from Roche.

\section{Authors' contributions}

CC2 and JK were mainly responsible for explaining the structure of the model. AP, CC1, CS, JFM and JM participated together in an advisory board to recommend data to feed the inputs of the model and afterwards analysed and interpreted the generated outputs. FA provided scientific consultancy and was a contributor in writing the manuscript. All authors read and approved the final manuscript.

Ethics approval and consent to participate

Not applicable.

\section{Consent for publication}

Not applicable.

\section{Competing interests}

The authors have read and understood the editorial policies on declaration of interests and declare the following interests: Conceição Saldanha has received consulting fees and honorarium from Roche Sistemas Diagnósticos Lda. as well as supports for travel to meetings for the study. José Maria Moutinho has received consulting fees from Roche Sistemas Diagnósticos, Lda. Carlos Catalão is an employee of Roche Sistemas Diagnósticos, Lda. and Jari Kempers is an employee of Roche Diagnostics the Netherlands. Fernando Arrobas works for Datamedica, Consultoria e Serviços em Bioestatística, Lda., a company that has a non-disclosure agreement with Roche Sistemas de Diagnóstico, Lda. for conducting their research studies on this matter. Ângela Pista, Carlos Costa and José Alberto Fonseca Moutinho declare they have not received any financial compensation for their participation in this study.

\section{Publisher's Note}

Springer Nature remains neutral with regard to jurisdictional claims in published maps and institutional affiliations.

\section{Author details}

${ }^{1}$ Present address: National Institute of Health, National Reference Laboratory of Gastrointestinal Infections, Lisbon, Portugal. ${ }^{2}$ Research Centre for Public Health, Public Health National School, New University of Lisbon, Lisbon, Portugal. ${ }^{3}$ Cytology Department, Unilabs, Oporto, Portugal. ${ }^{4}$ Health Sciences Faculty, Beira Interior University, Covilhã, Portugal. ${ }^{5}$ Child and Women Health Department, Cova da Beira Hospital Center, Covilhã, Portugal. ${ }^{6}$ Gynaecologic Oncology Department, CUF Hospital, Oporto, Portugal. Datamedica, Biostatistics Services and Consulting, Lisbon, Portugal. ${ }^{8}$ Roche Diagnostic Systems, Lisbon, Portugal. ${ }^{9}$ Roche Diagnostics, Almere, the Netherlands.

Received: 30 July 2018 Accepted: 12 February 2019

Published online: 26 February 2019

\section{References}

1. Bruni L, Barrionuevo-Rosas L, Albero G, Serrano B, Mena M, Gómez D et al. ICO Information Centre on HPV and Cancer (HPV Information Centre). Human Papillomavirus and Related Diseases in the World. Summary Report 15 December 2016. http://www.hpvcentre.net/statistics/reports/XWX.pdf. Acessed 2017-04-03.

2. Insinga RP, Dasbach EJ, Elbasha EH. Assessing the annual economic burden of preventing and treating anogenital human papillomavirus-related disease in the US: analytic framework and review of the literature. Pharmacoeconomics. 2005;23(11):1107-22.

3. Ronco G, Dillner J, Elfström KM, Tunesi S, Snijders PJ, Arbyn M, et al. Efficacy of HPV-based screening for prevention of invasive cervical cancer: follow-up of four European randomised controlled trials. Lancet. 2014;383(9916):524-32. 
4. Cuzick J, Thomas Cox J, Zhang G, Einstein MH, Stoler M, Trupin S, et al. Human papillomavirus testing for triage of women with low-grade squamous intraepithelial lesions. Int J Cancer. 2013 Feb 15;132(4):959-66.

5. HPV infection and cervical, vulvar and vaginal intraepithelial neoplasia. Consensus document. Portuguese Society of Gyneacology. 2014. http:// www.spginecologia.pt/uploads/Livro-de-Consenso-prova-3-FINAL.pdf. Acessed 14 Feb 2019.

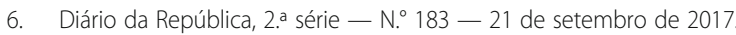

7. Statistics Nlo. Resident population. 2013. http://www.ine.pt/xportal/ xmain?xpid=|NE\&xpgid=ine_indicadores\&indOcorrCod=0003182\&selTab= tab0. Accessed 2015-04-22.

8. Relatório de Monitorização e Avaliação dos Rastreios Oncológicos. Lisboa: Direcção-Geral da Saúde, 2017.

9. Del Mistro A, Frayle H, Ferro A, Callegaro S, et al. Cervical cancer screening by high risk HPV testing in routine practice: results at one year recall of high risk HPV-positive and cytology-negative women. J Med Screen. 2014 Mar; 21(1):30-7.

10. Kulasingam SL, Havrilesky L, Ghebre R, Myers ER. Screening for Cervical Cancer: A Decision Analysis for the U.S. Preventive Services Task Force. Agency for Healthcare Research and Quality (US). 2011.

11. Insinga RP, Dasbach EJ, Elbasha EH, Liaw KL, Barr E. Progression and regression of incident cervical HPV 6, 11, 16 and 18 infections in young women. Infect Agent Cancer. 2007;2:15.

12. Khan MJ, Castle PE, Lorincz AT, Wacholder S, Sherman M, Scott DR, et al. The elevated 10-year risk of cervical precancer and cancer in women with human papillomavirus (HPV) type 16 or 18 and the possible utility of type-specific HPV testing in clinical practice. J Natl Cancer Inst. 2005 Jul 20;97(14):1072-9.

13. Insinga RP, Dasbach EJ, Elbasha EH. Epidemiologic natural history and clinical management of human papillomavirus (HPV) disease: a critical and systematic review of the literature in the development of an HPV dynamic transmission model. BMC Infect Dis. 2009 Jul 29:9:119.

14. Kataja V, Syrjänen $K$, Mäntyjärvi R, Väyrynen $M$, Syrjänen $S$, Saarikoski $S$, et al. Prospective follow-up of cervical HPV infections: life table analysis of histopathological, cytological and colposcopic data. Eur J Epidemiol. 1989:5(1):1-7.

15. Holowaty P, Miller AB, Rohan T, To T. Natural history of dysplasia of the uterine cervix. J Natl Cancer Inst. 1999:91(3):252-8.

16. Matsumoto K, Yasugi T, Oki A, Fujii T, Nagata C, Sekiya S, et al. IgG antibodies to HPV16, 52, 58 and 6 L1-capsids and spontaneous regression of cervical intraepithelial neoplasia. Cancer Lett. 2006;231(2):309-13.

17. Omori M, Hashi A, Nakazawa K, Yuminamochi T, Yamane T, Hirata S, et al. Estimation of prognoses for cervical intraepithelial neoplasia 2 by p16INK4a immunoexpression and high-risk HPV in situ hybridization signal types. Am J Clin Pathol. 2007;128(2):208-17.

18. Guedes AC, Zeferino LC, Syrjänen KJ, Brenna SM. Short-term outcome of cervical intraepithelial neoplasia grade 2: considerations for management strategies and reproducibility of diagnosis. Anticancer Res. 2010:30(6):2319-23.

19. McCredie MR, Sharples KJ, Paul C, Baranyai J, Medley G, Jones RW, et al. Natural history of cervical neoplasia and risk of invasive cancer in women with cervical intraepithelial neoplasia 3: a retrospective cohort study. Lancet Oncol. 2008;9(5):425-34.

20. Age-Adjusted SEER Incidence and U.S. Death Rates and 5-Year Relative Survival (Percent) By Primary Cancer Site, Sex and Time Period. Institute NC. 2015. http://seer.cancer.gov/csr/1975_2012/results_merged/topic_survival. pdf. Accessed 2015-12-09.

21. Bulkmans NW, Berkhof J, Bulk S, Bleeker MC, van Kemenade FJ, Rozendaal L, et al. POBASCAM study group. High-risk HPV type-specific clearance rates in cervical screening. Br J Cancer. 2007;96(9):1419-24.

22. Matsumoto K, Oki A, Furuta R, Maeda H, Yasugi T, Takatsuka N, et al. Japan HPV and cervical cancer (JHACC) study group. Tobacco smoking and regression of low-grade cervical abnormalities. Cancer Sci. 2010;101(9):2065-73.

23. Meyskens FL Jr, Surwit E, Moon TE, Childers JM, Davis JR, Dorr RT, et al. Enhancement of regression of cervical intraepithelial neoplasia II (moderate dysplasia) with topically applied all-trans-retinoic acid: a randomized trial. J Natl Cancer Inst. 1994;86(7):539-43.

24. Castle PE, Rodríguez AC, Burk RD, Herrero R, Hildesheim A, Solomon D, et al. Neither one-time negative screening tests nor negative colposcopy provides absolute reassurance against cervical cancer. Int J Cancer. 2009; 125(7):1649-56.
25. Pista A, de Oliveira CF, Cunha MJ, Paixao MT, Real O. Prevalence of human papillomavirus infection in women in Portugal: the CLEOPATRE Portugal study. Int J Gynecol Cancer. 2011;21(6):1150-8.

26. Pista A, de Oliveira CF, Lopes C, Cunha MJ. Human papillomavirus type distribution in cervical intraepithelial neoplasia grade $2 / 3$ and cervical cancer in Portugal: a CLEOPATRE II study. Int J Gynecol Cancer. 2013;23(3):500-6.

27. Wright TC Jr, Stoler MH, Behrens CM, Apple R, Derion T, Wright TL. The ATHENA human papillomavirus study: design, methods, and baseline results. Am J Obstet Gynecol. 2012;206(1):46.e41-11.

28. Castle PE, Stoler MH, Wright TC Jr, Sharma A, Wright TL, Behrens CM. Performance of carcinogenic human papillomavirus (HPV) testing and HPV16 or HPV18 genotyping for cervical cancer screening of women aged 25 years and older: a subanalysis of the ATHENA study. Lancet Oncol. 2011 Sep;12(9):880-90.

29. Administration HSC. Rates regulation of the institutions and integrated services in the National Health Service. 2014. http://ipst.pt/files/IPST/ LEGISLACAO/Legislacao_Nacional/Legislacao_Geral/tabela_precos_SNS 2014.pdf. Acessed 03-04-2017.

30. Costa C. Quadrivalent HPV Vaccination Impact in Portugal: 2007-2010. Presentation, EUROGIN conference; 2011; Lisbon.

31. Santana R, Lopes $S$, Costa C. Human papillomavirus disease burden in Portugal. Lisbon: Poster presentation, EUROGIN; 2011.

32. Dijkstra MG, van Niekerk D, Rijkaart DC, van Kemenade FJ, Heideman DA, Snijders PJ, et al. primary hrHPV DNA testing in cervical cancer screening: how to manage screen-positive women? A POBASCAM trial substudy. Cancer Epidemiol Biomark Prev. 2014;23(1):55-63.

33. Stanczuk GA, Baxter GJ, Currie H, Forson W, Lawrence JR, Cuschieri K, et al. Defining optimal triage strategies for hrHPV screen-positive women-an evaluation of HPV 16/18 genotyping, cytology, and p16/Ki-67 Cytoimmunochemistry. Cancer Epidemiol Biomark Prev. 2017;8.

34. Wright TC, Stoler MH, Behrens CM, Sharma A, Zhang G, Wright TL. Primary cervical cancer screening with human papillomavirus: end of study results from the ATHENA study using HPV as the first-line screening test. Gynecol Oncol. 2015;136(2):189-97.

35. Wright TC Jr, Stoler MH, Behrens CM, Sharma A, Sharma K, Apple R. Interlaboratory variation in the performance of liquid-based cytology: insights from the ATHENA trial. Int J Cancer. 2014;134(8):1835-43.

36. Wright T, Huang J, Baker E, Garfield S, Hertz D, Cox JT. The budget impact of cervical cancer screening using HPV primary screening. Am J Manag Care. 2016;22(3):e95-105.

37. Skroumpelos A, Agorastos T, Chatzistamatiou K, Akalestos T, Poulios N, Kyriopoulos J. Budget impact analysis of high-risk Hpv Dna (Hrhpv) test with 16/18 genotyping as a primary screening method for cervical cancer in Greece. Value Health. 2015;18(7):A349.

38. Petry KU, Barth C, Wasem J, Neumann A. A model to evaluate the costs and clinical effectiveness of human papilloma virus screeningcompared with annual papanicolaou cytology in Germany. Eur J Obstet Gynecol Reprod Biol. 2017;212:132-9.

39. Tjalma WAA, Kim E, Vandeweyer K. The impact on women's health and the cervical cancer screening budget of primary HPV screening with dual-stain cytology triage in Belgium. Eur J Obstet Gynecol Reprod Biol. 2017;212:171-81.

40. Elfström KM, Smelov V, Johansson AL, Eklund C, Nauclér P, ArnheimDahlström $L$, et al. Long term duration of protective effect for HPV negative women: follow-up of primary HPV screening randomised controlled trial. BMJ. 2014;348:9130.

41. Bulkmans NW, Rozendaal L, Snijders PJ, Voorhorst FJ, Boeke AJ, Zandwijken GR, et al. POBASCAM, a population-based randomized controlled trial for implementation of high-risk HPV testing in cervical screening: design, methods and baseline data of 44,102 women. Int J Cancer. 2004;1 10(1):94-101.

42. Kitchener HC, Almonte M, Gilham C, Dowie R, Stoykova B, Sargent A, et al. ARTISTIC: a randomised trial of human papillomavirus (HPV) testing in primary. Health Technol Assess. 2009;13(51):1-150 iii-iv.

43. Ronco G, Giorgi-Rossi P, Carozzi F, Confortini M, Dalla Palma P, Del Mistro A, et al. Efficacy of human papillomavirus testing for the detection of invasive cervical cancers and cervical intraepithelial neoplasia: a randomised controlled trial. Lancet Oncol. 2010;11(3):249-57.

44. Canfell K, Caruana M, Gebski V, Darlington-Brown J, Heley S, Brotherton J, et al. Cervical screening with primary HPV testing or cytology in a population of women in which those aged 33 years or younger had previously been offered HPV vaccination: results of the Compasspilot randomised trial. PLoS Med. 2017;14(9):e1002388. 
45. Ogilvie GS, van Niekerk D, Krajden M, Smith LW, Cook D, Gondara L, et al. Effect of screening with primary cervical HPV testing vs cytology testing on high-grade cervical intraepithelial neoplasia at 48 months: the HPV FOCAL randomized clinical trial. JAMA. 2018:320(1):43-52.

46. Katki HA, Kinney WK, Fetterman B, Lorey T, Poitras NE, Cheung L, et al. Cervical cancer risk for women undergoing concurrent testing for human papillomavirus and cervical cytology: a population-based study in routine clinical practice. Lancet Oncol. 2011;12(7):663-72

47. Cuzick J, Clavel C, Petry KU, Meijer CJ, Hoyer H, Ratnam S, et al. Overview of the European and north American studies on HPV testing in primary cervical cancer screening. Int J Cancer. 2006;119(5):1095-101.

48. Richardson LA, El-Zein M, Ramanakumar AV, Ratnam S, Sangwa-Lugoma G, Longatto-Filho A, et al. HPV DNA testing with cytology triage in cervical cancer screening: influence of revealing HPV infection status. Cancer Cytopathol. 2015:123(12):745-54.

49. Bergeron C, Giorgi-Rossi P, Cas F, Schiboni ML, Ghiringhello B, Dalla Palma P, et al. Informed cytology for triaging HPV-positive women: substudy nested in the NTCC randomized controlled trial. J Natl Cancer Inst. 2015;7:107(2).

50. Bianchi FP, Gallone MS, Fortunato F, Boccalini S, Martinelli D, Prato R, et al. Epidemiology and cost of cervical cancer care and prevention in Apulia (Italy), 2007/2016. Ann Ig. 2018;30(6):490-501.

51. Arbyn M, Snijders PJ, Meijer CJ, Berkhof J, Cuschieri K, Kocjan BJ, Poljak M. Which high-risk HPV assays fulfil criteria for use in primary cervical cancer screening? Clin Microbiol Infect. 2015;21(9):817-26.

Ready to submit your research? Choose BMC and benefit from:

- fast, convenient online submission

- thorough peer review by experienced researchers in your field

- rapid publication on acceptance

- support for research data, including large and complex data types

- gold Open Access which fosters wider collaboration and increased citations

- maximum visibility for your research: over $100 \mathrm{M}$ website views per year

At $\mathrm{BMC}$, research is always in progress.

Learn more biomedcentral.com/submissions 